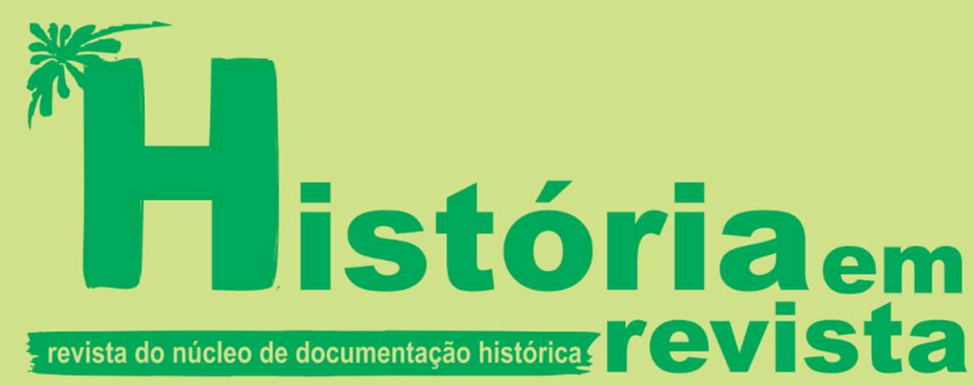

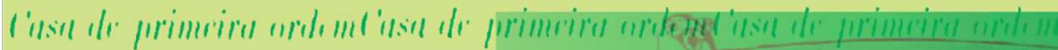

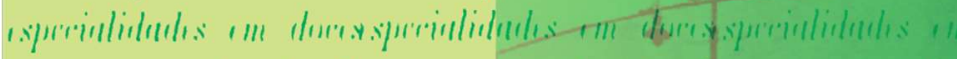

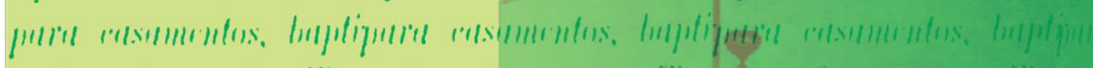

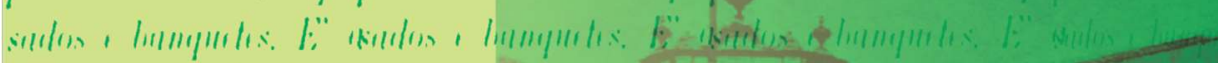

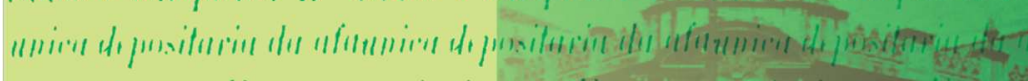

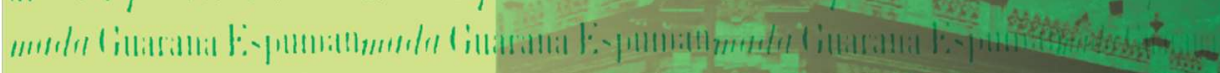

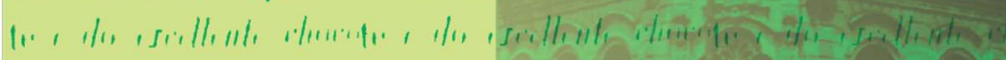

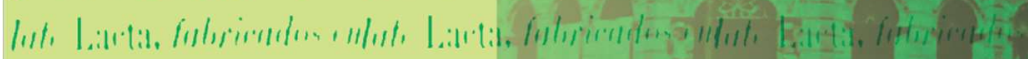

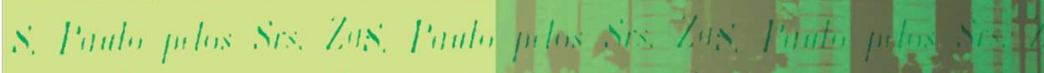

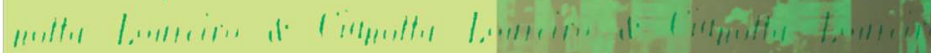

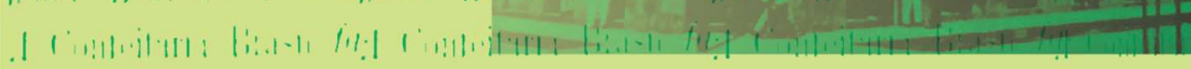




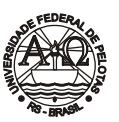

Obra publicada pela Universidade Federal de Pelotas Reitor: Pedro Rodrigues Curi Hallal Vice-Reitor: Luis Isaías Centeno do Amaral

Chefe de Gabinete: Aline Elias Lamas

Pró-Reitor de Graduação: Maria de Fátima Cóssio

Pró-Reitor de Pesquisa e Pós-Graduação: Flávio Fernando Demarco

Pró-Reitor de Extensão e Cultura: Francisca Ferreira Michelon

Pró-Reitor de Planejamento e Desenvolvimento: Otávio Martins Peres

Pró-Reitor Administrativo: Ricardo Hartlebem Peter

Pró-Reitor de Infra-estrutura: Julio Carlos Balzano de Mattos

Pró-Reitor de Assuntos Estudantis: Mário Renato de Azevedo Jr.

Pró-Reitor de Gestão Pessoas: Sérgio Batista Christino

\section{CONSELHO EDITORLAL}

Representante das Ciências Agronômicas: Guilherme Albuquerque de Oliveira Cavalcanti (Titular), Cesar Valmor Rombaldi (suplente) e Fabrício de Vargas Arigony Braga (suplente) | Representantes da Área das Ciências Exatas e da Terra: Adelir José Strieder (titular) e Juliana Pertille da Silva (suplente) | Representante da Área das Ciências Biológicas: Raquel Ludke (suplente) | Representante da Área das Engenharias e Computação: Darci Alberto Gatto | Representantes da Área das Ciências da Saúde: Claiton Leoneti Lencina (titular) e Giovanni Felipe Ernst Frizzo (suplente) | Representante da Área das Ciências Sociais Aplicadas: Célia Helena Castro Gonsales | Representante da Área das Ciências Humanas: Charles Pereira Pennaforte e Guilherme Camargo Massaú (suplente) | Representantes da Área das Linguagens e Artes: Josias Pereira da Silva (titular) e Maristani Polidori Zamperetti (suplente)

\section{INSTITUTO DE CIÊNCLAS HUMANAS}

Diretor: Prof. Dr. Sidney Gonçalves Vieira

Vice-Diretor: Prof. Dr. Sebastião Peres

\section{NÚCLEO DE DOCUMENTACÃO HISTÓRICA}

Coordenadora:

Prof ${ }^{a}$ Dra. Lorena Almeida Gill

Membros do NDH:

Prof ${ }^{a}$ Dra. Beatriz Ana Loner

Prof ${ }^{a}$ Dra. Lorena Almeida Gill

Prof. Dr. Paulo Ricardo Pezat

Prof. Dr. Aristeu Elisandro Machado Lopes

Técnico Administrativo:

Paulo Luiz Crizel Koschier

HISTÓRIA EM REVISTA - Publicação do Núcleo de Documentação Histórica

Comissão Editorial:

Prof. Dr. Aristeu Elisandro Machado Lopes

Prof ${ }^{a}$ Dra. Beatriz Ana Loner

Prof ${ }^{a}$ Dra. Lorena Almeida Gill

Prof. Dr. Paulo Ricardo Pezat

Conselho Editorial:

Prof ${ }^{a}$ Dra. Helga I. Landgraf Piccolo (UFRGS)

Prof. Dr. René Gertz (UFRGS) (PUCRS)

Prof. Ms. Mario Osorio Magalhães (UFPel)

Prof. Dr. Temístocles A. C. Cezar (UFRGS)

Profa. Dra. Beatriz Teixeira Weber (UFSM)

Prof ${ }^{a}$. Dra. Maria Cecília V. e Cruz (UFBA)

Prof. Dr. Marcelo Badaró Mattos (UFF)

Profa. Dra. Joan Bak (Univ. Richmond - USA)

Prof. PhD Pablo Alejandro Pozzi (Universidad de Buenos Aires).

Prof. Tommaso Detti (Università Degli Studi di Siena)

Editor: Prof. Dr. Aristeu Elisandro Machado Lopes

Editoração e Capa: Paulo Luiz Crizel Koschier

Editora e Gráfica Universitária

R Lobo da Costa, 447 - Pelotas, RS - CEP 96010-150 |

Fone/fax: (53) 32278411

e-mail: editora@ufpel.edu.br

\section{Impresso no Brasil}

Edicão: 2017

ISSN - 1516-2095

Dados de catalogação na fonte: Aydê Andrade de Oliveira - CRB - 10/864

História em revista / publicação do Núcleo de Documentação Histórica. Instituto de Ciências Humanas. Universidade Federal de Pelotas. v.23, (dez. 2017). - Pelotas: Editora da UFPel, 2017.

$1 \mathrm{v}$.

Anual

ISSN 1516-2095

1. História - Periódicos. I. Núcleo de Documentação Histórica. Instituto de Ciências Humanas. Universidade Federal de Pelotas. CDD 930.005

\section{Indexada pela base de dados Worldcat Online Computer Library Center}

\section{PEDE-SE PERMUTA} WE ASK FOR EXCHANGE

UFPel/NDH/Instituto de Ciências Humanas

Rua Cel. Alberto Rosa, 154

Pelotas/RS - CEP: 96010-770

Caixa Postal 354

Fone: (53) 32843208

\section{http://wp.ufpel.edu.br/ndh/} e-mail:ndh.ufpel@gmail.com 


\title{
TEXTO DE MAR E TERRA: O CASO DO GUIA DOS BANHISTAS, 1890 - RIO GRANDE/RS
}

\author{
SEA AND LAND TEXT: THE CASE OF SWIMMERS GUIDE, 1890 - RIO \\ GRANDE/RS
}

Felipe Nobrega Ferreira ${ }^{1}$

\begin{abstract}
Resumo: O Guia dos Banhistas - Informações sobre a praia de banhos da Villa Sequeira era entregue na chegada dos passageiros à estação férrea, e também possuía cópias nas dependências do único hotel desse balneário inventado no ano de 1890, na cidade de Rio Grand/RS. Dessa forma, o presente analisa tal documento buscando evidenciar as representações que são elaboradas, e acionadas, tanto nos modos de ler, como na criação de um repertório de sensibilidades que se forjaram a partir dessa intersecção, até então inédita no território brasileiro, entre natureza litorânea e cultura. Por fim, do processo de desmontagem desse material, será possível encontrar uma praia que está para além do texto, e prende-se mesmo ao universo das representações, que dotam de sentido a existência do Guia, e também fornecem vestígios para o que chamamos de sensibilidades ambientais, as quais se constituiriam a partir dessa liminaridade permanente entre mar e terra.
\end{abstract}

Palavras-chave: Guia dos banhistas, praia, natureza e cultura, leitura

\section{Introdução}

Em 1890, ao desembarcar dos vagões Formiguinha e Andorinha no litoral da cidade de Rio Grande (RS), os passageiros recebiam um pequeno livreto intitulado Guia dos Banhistas - Informações sobre a praia de banhos da Villa Sequeira. A cena se repetia no hotel do recém-inaugurado balneário para banhos de mar, quando os hóspedes poderiam acessar esse mesmo material que tratava de informar tanto sobre a própria localidade, então chamada de Villa Sequeira, como também versava sobre as formas adequadas para utilizar o espaço costeiro.

Impresso no ano de 1890 pela Typographia da Livraria Rio-Grandense, e sem registro de reedições, ou declaração de autoria, ele é composto por vinte três páginas divididas em seis capítulos, sendo que dois deles são excertos da obra As praias de Portugal (1876), do lisboeta Ramalho Ortigão. Assim, levando em consideração esse documento, buscamos evidenciar as representações elaboradas e acionadas, tanto nos modos de ler, como na

${ }^{1}$ Fundação Universidade Federal do Rio Grande. Doutorando do Programa de PósGraduação em Educação Ambiental. ffnobrega@yahoo.com.br 
criação de um repertório de sensibilidades que se forjaram a partir dessa intersecção entre natureza litorânea e cultura, elaborando algo até então inédito no território brasileiro, a invenção da praia moderna.

Ao propor tal análise, o diálogo com a História Cultural se faz evidente, e encontra nas palavras de Sandra Pesavento um norte teórico quando diz:

A história cultural tem se empenhado, entre outras coisas, a resgatar estas sensibilidades do passado, ou as práticas culturais do sensível, através das marcas que deixaram nos materiais e arquivos, nas artes e na literatura (PESAVENTO, 2007, p. 93).

A questão das sensibilidades na História foi amplamente debatida por essa autora que, no escopo de sua produção, tratou de evidenciar as possibilidades do que chamava de um "giro teórico", quando seria preciso colocar "novos óculos para enxergar a realidade" (PESAVENTO, 2008, p. 56). Nesse sentido, a sua explicitação do que seria uma história do sensível ganha uma interessante síntese na seguinte passagem:

Recuperar sensibilidades não é sentir da mesma forma, é tentar explicar como poderia ter sido a experiência sensível de um outro tempo pelos rastros que deixou. $O$ passado encerra uma experiência singular de percepção e representação do mundo, mas os registros que ficaram, e que é preciso saber ler, nos permitem ir além da lacuna, do vazio, do silêncio (PESAVENTO, 2007, p. 21).

Se o Guia dos Banhistas pode ser considerado uma dessas marcas do sensível, está na liminaridade entre natureza e cultura, como essa relação é pensada e dada a ler, que os "novos óculos" propostos por Pesavento surgem. E nesse texto a aproximação com outro campo do conhecimento será essencial para repensar esse material em termos teóricos e metodológicos, no caso, a presença da Educação Ambiental enquanto área que se dedica ao estudo, justamente, dessa intersecção entre sociedade e natureza a partir de um posicionamento crítico que perfaz a trajetória dos seus próprios fundamentos 2 .

Nesse sentido, a concepção de Educação Ambiental de Isabel Cristina de Moura deixa bastante claro um diálogo possível:

2 Aqui é possível citar um marco basilar do campo, o Tratado de Educação Ambiental para Sociedades Sustentáveis e Responsabilidade Global, documento escrito no contexto do Fórum Internacional de ONG's, atividade paralela ao Rio-92, evento oficial da Conferências das Nações Unidas para o Meio Ambiente e Desenvolvimento, que ocorreu no Rio de Janeiro. 
A busca dos sentidos da ação humana que estão na origem dos processos socioambientais parece sintetizar bem o cerne do fazer interpretativo em educação ambiental. Ao evidenciar os sentidos culturais e políticos em processos de interação sociedade-natureza, o educador seria um intérprete das percepções - que também são, por sua vez - interpretações humanas no meio ambiente (CARVALHO, 2002, p. 31).

Aqui ela se refere ao papel desse pesquisador educador-ambiental, ao qual atribui a responsabilidade de ser um interprete do sensível junto às sociedades. A mesma autora não deixa de dizer, logo em seguida, que esses sentidos instituem formas de relação com o ambiente, e por isso são passíveis de investigações de cunho interpretativo, como também frisa que esses "sentidos" se configuram dentro de determinadas comunidades humanas, e dentro de um tempo específico (CARVALHO, 2002, p. 32).

Retornando à História Cultural, a própria Sandra Pesavento (2008) já apontava uma aproximação com a história ambiental, por exemplo, no que tange a investigação ligada às sensibilidades. É tratando de conjugar essas perspectivas, num exercício científico que Enrique Leff entende como "saber ambientalizado" (LEFF, 2001) que a utilização do termo sensibilidades ambientais ganha projeção.

O Guia dos Banhistas, então, é um acesso ao sensível a partir do universo da escrita, do documento textual. E por isso, a importância de pensalo dentro de um processo que Roger Chartier entende que vai da criação do suporte em si até:

as modalidades partilhadas do ler - as quais dão formas e sentidos aos gestos individuais -, e que coloca no centro da sua interrogação os processos pelos quais, face a um texto, é historicamente produzido um sentido e diferenciadamente construída uma significação (CHARTIER, 1990, p. 121)

Assim, o que está em jogo é a análise desses modos de ler que forjam práticas e estabelecem representações sociais as quais interagem, na mesma medida em que se transformam por meio de constantes reapropriações dos sujeitos. Da mesma maneira, o conteúdo do texto é, igualmente, um produtor de sentidos, e que nesse caso específico projetam representações dessa relação natureza e cultura a qual buscamos interrogar.

Nesse percurso interpretativo, as evidências do sensível emergem e se transformam, também, em texto. Agora um outro, que fala sobre como se inventou uma praia no extremo meridional brasileiro. 


\title{
Uma praia e seu Guia: um documento sensível
}

Logo no primeiro parágrafo intitulado "a invenção da praia", o historiador do sensível Alain Corbn explicita aos seus leitores:

\begin{abstract}
O modo de apreciar o mar, o olhar dirigido às populações que frequentam suas margens, não resultam apenas do tipo, do nível de cultura, as sensibilidade própria do indivíduo. A maneira de estar junto, a convivência entre turistas, os signos de reconhecimento e os procedimentos de distinção condicionam igualmente as modalidades de fruição do lugar. O emprego do tempo e o arranjo do espaço impostos pelas formas de sociabilidade que se organizam para depois se manifestarem à beira-mar, a gama de distrações, dos prazeres e das obrigações que daí resultam, esboçam a vilegiatura marítima, por enquanto em gestação (CORBIN, 1989, p. 266).
\end{abstract}

Nessa passagem, Corbin apresenta os pontos fundamentais daquilo que ele concebe como o conjunto de práticas e experiências que caracterizariam que chama de "invenção da praia". Invenção essa que ele localiza no século XIX, quando a relação com a natureza litorânea passa por transformações e ressignificações no cenário europeu.

É possível pensar a Villa Sequeira nesses termos quando pensamos suas práticas, ou seja, ela passa por um processo de invenção, quando o mar deixa de ser somente um dado geográfico, físico, e passa a ganhar sentidos que, por exemplo, o Guia dos Banhistas ajuda a observar nesse processo de investigação histórica. Esse documento propõe um mar, uma praia, uma forma de relação com a natureza que está conectada a fundação oficial desse local em 1890.

E se esse é o ano de fundação, aqui é preciso localizar com um pouco mais de cuidado as marcas dessa invenção, que não se restringe a tal data. Quando, em 1884, o sócio majoritário empresa Carris Urbanos do Rio Grande, que depois viria ser o fundador do balneário, Antonio Candido de Sequeira adquire os direitos de exploração da linha litorânea de Rio Grande chamada de Distrito da Mangueira - estamos diante de um primeiro indício de invenção (FERREIRA, 2012). Quem iria explorar uma linha de trem até a costa sem dela fazer algum tipo de exploração que não fosse ligada a sua própria condição litorânea em tempos de propagação dessa modernidade3?

Isso irá se confirmar em 1886, quando Sequeira apresenta um prospecto de exploração desse distrito costeiro. Daí em diante as construções começam a ser feitas, dando os moldes desse balneário localizado a pouco

3 Aqui a obra de Da Rua ao tetro (2007) é um importante demonstrativo das experiências modernas vividas pela cidade de Rio Grande no século XIX. 
mais de $20 \mathrm{~km}$ do perímetro urbano da cidade de Rio Grande. A invenção estava em curso, e o ano de 1890 marca a transição de uma localidade relegada ao abandono público ao inerente processo de ocupação costeira a partir do mais variado leque de possibilidades que se abriam aos sujeitos que buscavam à costa (FERREIRA, 2012).

E aqui um detalhe importante a frisar: ao analisar o Guia dos Banhistas, estamos diante de um manual de regulação e civilidade para os banhistas, os primeiros banhistas dessa costa. Há um caráter educativo, de criar as justificativas, motivos, sensibilidades a serem acessadas de um modo geral para que os homens e mulheres passassem a fazer uso dos banhos de mar em seu cotidiano de verão. E isso se dá no plano tanto da criação desse desejo, como na sua efetiva fruição no momento de experienciar essa intersecção que se estabelece entre mar, terra e todo o seu cenário balnear - praia, areia, hotel, jogos, festas, competições, manutenção de horários...

Sendo assim, o Guia dos Banhistas está como a materialização de sensibilidades, com suas marcas de historicidade e indícios em que o olhardetetive do pesquisador deve ser acionado para interpretar tais sinais, estabelecendo nexos e relações para se aproximar de um passado onde os sujeitos passaram a procuravam a praia. Levando isso em consideração, o Guia é tratado aqui como um manual civilizatório dos banhos de mar.

Quando se utiliza o termo "civilizatório" estamos remetendo à clássica obra de Norbert Elias, O Processo Civilizador. No sentido que o autor propõe, percebendo esse conceito enquanto um constructo do próprio Ocidente em relação a si mesmo (ELIAS, 2011, p. 23), e referindo-se a uma sociedade de corte, o que se projeta é sempre a criação de direcionamentos sociais em prol de uma normatização das atitudes, da modulação de posturas, o controle dos sentimentos que forjam não só a alteridade da barbárie, igualmente construída, como também imbrica os sujeitos em uma sociedade na qual aqueles que melhor controle tiverem sobre suas paixões, maior êxito alcançarão nesse processo civilizatório. Maria Pilla realiza uma leitura bastante ilustrativa da obra de Elias quando diz:

\footnotetext{
Ou seja, é preciso alcançar o autocontrole, bem como ter atitudes pensadas, ter o hábito de 'ligar os fatos em cadeias de causa e efeito', ser previdente e prudente ao tomar atitudes. Aí está a mudança 'civilizadora' do comportamento pensada por Elias. É a valorização do autocontrole e comedimento (PILLA, 2003, p. 6).
}

Ao longo de todo o século XIX, e principalmente na primeira metade dos novecentos, a edição e reedição de vários manuais de civilidade e etiqueta circulariam pelo Brasil. Considerável reforço e divulgação desse tipo de 
material seria dado pelos periódicos, que apresentavam esses manuais como "indispensáveis" para aqueles que desejassem ser bem sucedidos em sociedade (RAINHO apud CAMPOS, 2007, p. 3).

Um manual de banhos é elemento praticamente nulo no que tange a historiografia que trabalha com o litoral brasileiro de banhos, sendo que a única referência a um guia semelhante diz respeito à praia de Mar Del Plata. Gustavo Valleja informa que, em 1888 foi, produzido um "Reglamento de Baños" que ficaria em vigor por muitos anos e possuía como foco: “'adecentar' la drástica irrupción de lo privado em lo espacio publico, contenida en la exhibición con mayor naturalidad de cuerpos desprovistos de la necessária distancia que establecia la 'etiqueta', ante la presencia del 'outro"' (VALLEJA, 2002, p. 108).

A aproximação possível com esse regramento de banhos se dá em função, justamente, do caráter civilizatório proposto pelo documento. Ambos versam sobre práticas apropriadas à convivência junto ao espaço de praia, numa relação que se dá tanto com o uso dos banhos em si, como da experiência social dento desse cotidiano de verão.

No caso do Guia dos Banhistas, quando passamos a realizar um processo de desmontagem (LE GOFF, 2003) dessa fonte, é preciso lembrar dos apontamentos de Roger Chartier: "Uma vez saídos das prensas, o livro, seja ele qual for, está susceptível a uma multiplicidade de usos. Ele é feito para ser lido, claro, mas as modalidades do ler são, elas próprias, múltiplas, diferentes segundo épocas, os lugares, os ambientes" (CHARTIER, 2004, p. 173).

Embora o foco aqui não seja com os leitores da França do século XVIII, os apontamentos de Chartier colaboram para pensar o alcance desse documento no que tange ao suporte e as modalidades de ler. Assim, sobre o primeiro item, logo percebemos uma porta que se abre ao mundo de interconexões que projetam esse sentir no tempo pelos sujeitos.

Possuindo o formato de um livreto, esse manual de banhos possui semelhanças com as revistas ilustradas do século XIX que não podem ser desconsideradas. Seguem as imagens que possibilitam essa interpretação: 
FIGURA 1 - Guia dos Banhistas, FIGURA 2 - Revue des Deux 1890. Mondes
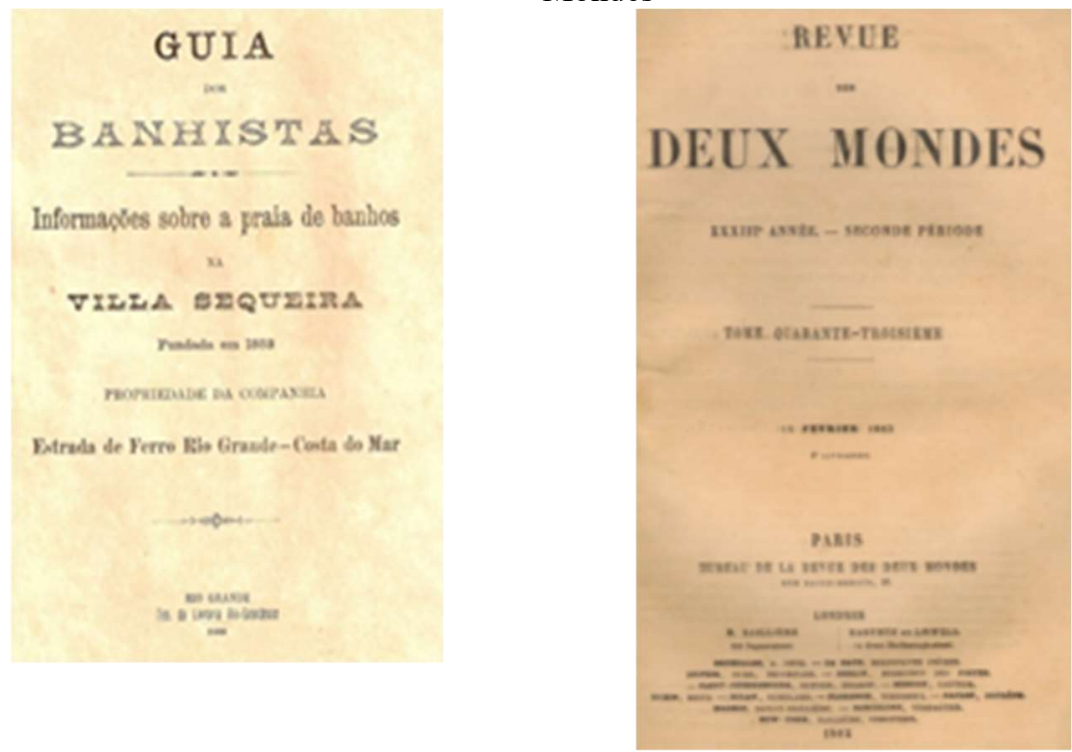

Fonte: Acervo do Centro Histórico

Fonte:

Disponível

em< de Documentação Histórica da Universidade Federal do Rio Grande $-\mathrm{CDH} / \mathrm{FURG}$

https://upload.wikimedia.org/wikiped ia/commons/f/f3/Revue_des_Deux_ Mondes.jpg> Acesso em 13/09/2017

A hierarquização das informações, com o título dividido em três momentos distintos, seguido de subtitulação e retomada de letras em destaque, a utilização de elementos gráficos de divisão (traços/linhas adornados ou simples), para logo em seguida expressar a data de edição, culminando com a localidade e nome da tipografia, parece oferecer um padrão estético tipográfico de similaridade perceptível. Assim se projeta um diálogo com aquela que seria uma das revistas de maior circulação no Brasil Império, a Revue Deux Mondes, como informa Ana Luiza Martins ao dizer que a Revue encontrou no território brasileiro um de seus melhores mercados, tornando-se um ícone do saber elitizado, fornecendo ao seu leitor informações sobre o que havia de mais moderno do outro lado do Atlântico (MARTINS, 2008, p. 75).

Nesse sentido, Martins ainda pontua que tais revistas buscavam romper 
com a formatação rígida dos periódicos, sendo que tais projetos editoriais levados a cabo no período enfrentavam todo tipo de dificuldades: "gráficas precárias, população analfabeta e mesmo pontos de vendas, raras bibliotecas públicas e editoração praticamente inexistente" (MARTINS, 2008, p. 42).

Circulando pelo país, não seria diferente naquela instituição que possuía substancial acervo em termos nacionais no século XIX, a Bibliotheca RioGrandense. Pensar na circulação desse tipo de material gráfico em Rio Grande, portanto, não consistiria em nenhuma surpresa ou descalabro.

$\mathrm{E}$ aqui cabe uma pequena digressão levando em consideração o fundador do balneário, Antonio Candido de Sequeira, nascido na cidade de Rio Grande em 1847. Dentro de sua trajetória de vida, nas mais diversas agências sociais que estabeleceu ao sair de Rio Grande ainda jovem para estudar em Petrópolis, apropriar-se de toda herança familiar por meio de uma série de procurações que seus três irmãos lhe forneceram, viajar para Inglaterra, transformar-se em agente de leilões em Porto Alegre, retornar a sua cidade natal como proprietário de uma empresa que resgatava navios que sofriam sinistros na barra de acesso ao porto rio-grandino, comprar a concessão de transporte urbano na mesma cidade e, por fim, estender as linhas de trem até à costa para inventar um balneário (FERREIRA, 2012, p. 66).

Tal fato se faz necessário expor em função do papel que esse sujeito tem na articulação dessa praia de banhos, envolvendo-se em todo o processo de invenção balnear diretamente, não sendo possível desvincular a sua figura, e o repertório de práticas e representações que estabeleceu em cada uma de suas experiências, dessa trama. Sequeira, da mesma forma, batiza a localidade com o seu nome, a Villa Sequeira - o que demonstra uma espécie de unidade ligada a sua figura em relação a esse ambiente construído em Rio Grande.

Por não possuir autoria identificada, apenas uma assinatura do "Gerente" como se fosse dado um aval ao final do conteúdo exposto, o Guia dos Banhistas aqui é entendido, igualmente, como fruto dessas intervenções de Sequeira em cada elemento que veio a constituir a praia de banhos. Um documento desse porte, de circulação efetiva desde a primeira chegada de trem, com distribuição na estação férrea, e também dentro do hotel em que ele era o proprietário, só poderia ser distribuído com a aprovação editorial de Sequeira, da mesma forma que contém informações que só poderiam ser apresentadas por ele, dado o seu envolvimento e desejo empresarial baseado naquilo que buscava consolidar.

Ainda, quanto ao suporte, devem ser levadas em consideração as modalidades do ler, como apresenta Chartier. Primeiro a questão do tamanho, 
o qual facilita sua utilização rotineira, porém, é preciso pensar que tratam-se de vinte e uma páginas, com exceção da capa e contracapa, acrescentando aí um fator de leitura que deve ser feita exigindo do leitor atenção em diversos itens que estão presentes - de condições ligadas às estruturas físicas oferecidas, até as modalidades de banho de mar. Mesmo que a estrutura gráfica interna se mostre espaçada, com uma visualidade que obedece a um caráter pontuado por tópicos, a quantidade de informação é abrangente para corresponder a uma leitura que seria feita uma única vez.

Com isso, o caráter de manual, dentro de uma pedagogia civilizatória ligada à natureza costeira, parece se consolidar. $\mathrm{O}$ ato de poder e, justamente, fazer parte de seu caráter constitutivo ser acessado dentro de várias oportunidades ao longo da estadia desse sujeito que procurava a Villa Sequeira, configura um modo de ler específico.

E, nesse caso, mais uma vez demonstrando o caráter educativo, didático do Guia dos Banhistas - o que o próprio título possibilita sugerir a priori - é importante frisar o caráter inédito dos banhos de mar dentro desse cenário balnear no Brasil. Assim, sugerir a recorrência ao acesso a esse material textual é algo possível de ser sugerido tanto para o momento de confecção, quando foi pensando dentro do contexto dessa invenção por àqueles que o elaboraram (de Sequeira até os responsáveis da tipografia em questão), como por parte do público leitor.

E aqui um item que a própria Ana Luiza Martins (2008) reconhece como importante de considerar ao trabalhar com revistas ilustradas, mas que aqui também deve ser problematizado. No caso, a percepção de uma sociedade brasileira pouco letrada nesse período.

Dessa percepção factual da autora, e pensando um cenário rio-grandino que não foge a essa constante, é possível identificar um recorte de classe associado ao próprio documento, o qual possuía um público-alvo que, primeiramente, se constitui letrado, portanto, parte de uma fatia da sociedade que pode ser considerada privilegiada financeiramente nesse momento. Aprender os banhos fazendo uso desse material impresso está atrelado a uma classe social que, confirmando o caráter elitista da invenção da praia (CORBIN, 1989), é capaz de compreender o texto e suas referências contextuais naquele momento histórico.

Mesmo a compreensão estética está em jogo, já que o universo de similaridade tipográfica possui uma intencionalidade que não pode fugir a análise. A sedução que um material desses poderia produzir é intrínseca ao suporte e forma de comunicação que ele estabelece com os leitores, fazendo 
uso da referência de um padrão revistas que circulavam nesse período e, assim, gerando algum tipo de identificação imediata.

Um último elemento não pode ser desconsiderado quando pensamos o acesso a esse Guia dos Banhistas, e ele diz respeito à capacidade de reapropriações do sujeito em relação ao material no âmbito das práticas e representações cotidianas que passam a se forjar quando da experiência com o litoral. E assim é importante retomar um apontamento de Pesavento ao tratar da História Cultural, e também do "modo de olhar" dentro do universo das sensibilidades: "captar as razões e sentimentos de uma temporalidade já escoada é ter em mente a alteridade do passado, com sua diferença de códigos e valores" (PESAVENTO, 2005).

Entendendo que somos estrangeiros lidando com esse tempo já escoado, como ela diz: nesse passado que é um outro, sempre haverá o que escapa na análise. E isso está condicionado a essa percepção temporal, na qual projetamos algum tipo de inteligibilidade, e propomos o que a própria chamaria de "ficção controlada", quando, mesmo apresentando marcas de historicidade/registros desse tempo, algo está fora do nosso alcance.

Esse "algo", então, é a capacidade desses sujeitos do passado se reapropriarem, dentro das próprias experiências em que estão sendo atravessados, dos elementos que lhes foram dispostos. Por mais que outras fontes que não o Guia dos Banhistas possam confirmar muitas das situações apresentadas pelo documento, como é o caso dos periódicos do período em suas crônicas sobre o veraneio na cidade, a imprevisibilidade dos gestos, do pulsar sensível, sempre se encontrará aberta.

Assim, o investigador, como tanto Sandra Pesavento e Isabel Carvalho compreendem, realiza um, entre outros possíveis, exercícios de interpretação. Poderiam os banhistas-leitores desprezarem esse material? Não haveria correspondência alguma entre o texto e as práticas objetivas?

Por mais que aqui estejamos inclinados a perceber que sim, ocorreu uma relação direta entre a invenção da praia na cidade de Rio Grande e o Guia dos Banhistas enquanto manual civilizatório constituinte desse momento, está na possibilidade da dúvida o movimento da pesquisa que aprofunda esse debate. Sentir-se estrangeiro no tempo não é uma opção, mas sim um fato, o que nos leva a, continuamente, buscar os fios, os rastros, os pequenos indícios que são capazes de demonstrar a consolidação desse projeto que institui sensibilidades ambientais elaboradas a partir dessa tessitura que conecta mar e terra, entre natureza litorânea e cultura no Rio Grande do Sul. 


\section{Por dentro do Guia dos Banhistas: uma leitura possível}

Quando nossa análise se volta para o conteúdo textual do Guia dos Banhistas, as palavras de Starobinski, ao falar sobre o uso da literatura no campo da História, ganham especial sentido:

Um texto é uma totalidade relativamente limitada, cujos elementos constitutivos podem ser legitimamente relacionados uns com os outros: ele exige assim uma análise interna dos resultados, ainda que muito variáveis segundo os fatores e os níveis considerados, são sempre passíveis de um controle bastante preciso. Pois o texto tem direitos sobre o que se diz a seu respeito; ele representa para o discurso interpretativo, um ponto de referência que é impossível abandonar (STAROBINSKY, 1988, p. 139)

O autor faz uma lembrança do que poderia ser considerado um compromisso do pesquisador com o próprio texto, com o seu conteúdo, que se expressa dentro de um universo de referências próprio, concreto, e não um catálogo abstrato ao qual podemos manejar tão somente segundo nossos interesses. Mesmo que o Guia seja encarado como um manual civilizatório para banhos, o que está em jogo é um suporte que se vale do texto escrito permeado por representações de sua época, com estratégias aparentes da criação até as práticas que deseja imputar.

Daí sempre a importância de um retorno ao texto, esse que é portador de uma intencionalidade, a qual se declara, mas não se entrega inteiramente, provocando a obstinação de um melhor saber que é contínuo, como Starobinski (1988) irá propor em suas reflexões. Dessa forma, a cada retorno, a cada nova pergunta, são criadas estratégias de não ser seduzido pelo documento, o que no caso do Guia dos Banhistas trata-se de um exercício constante dado o seu teor, como veremos a seguir.

Como já informado, tratam-se de seis capítulos que obedecem a títulos específicos, sendo eles: Situação, O Tratamento Maritimo ${ }^{4}$, Precauções Hygienicas, Commodidades na praia, Habitações na Villa Siqueira e Salão de visitas e concertos, e de jogo. Dentro de cada capítulo ainda existem subtítulos, que organizam os assuntos a serem detalhados.

Dado o volume de material presente no Guia, e como existe um objetivo específico junto a esse artigo, optamos por uma análise dos elementos ligados a ocupação, e consequente impacto ambiental no sentido de manejo da natureza ali presente, bem como as práticas e representações que conjuguem essa mesma relação no âmbito de uma sociabilidade à beira-mar, fatores que se

\footnotetext{
${ }^{4}$ Optou-se aqui por manter a grafia do próprio documento em questão.
} 
conectam a essa perspectiva sensível ligada ao mar, e as transformações desse espaço costeiro em prol da invenção dessa praia moderna na cidade de Rio Grande.

Levando isso em consideração, logo no primeiro tópico o Guia dos Banhistas apresenta o que chama de "Situação", quando apresenta aspectos gerais do balneário recém-construído:

A praia de banhos Villa Sequeira está situada sobre a costa do Oceano Atlântico, a 8 kilometros ao sul da boca da barra do Estado do Rio Grande do Sul, no districto da Mangueira no município do Rio Grande (...) Abrange 300 metros ao longo da costa e cerca de 2200 metros de fundo, cortada ao meio pela linha férrea que a liga com a cidade do Rio Grande (GUIA DOS BANHISTAS, 1890, p. 3).

Uma extensa alameda é projetada, 2.200 metros de extensão por 40 metros de largura, cercada por terrenos de 100x50 metros, formando ruas de 16 metros de largura (GUIA DOS BANHISTAS, 1890). Em um dos subitens desse primeiro momento, de nome "natureza do solo", o documento diz:

Tornou-se necessário à companhia empregar avultado capital na acquisição de innumeros pequenos lotes de terras pertencentes a antigos possuidores, os quaes de forma alguma valorisavam estas terras - do que resultou que a sua apparencia era agreste, os caminhos intransitáveis, e constante a invasão das areias vindas do mar (GUIA DOS BANHISTAS, 1890, p. 4)

O Distrito da Mangueira tratava-se de uma terra destinada à criação de gado, que pouca menção merece nos relatórios municipais da Intendência nas décadas de 1870 e 1880. Com a concessão da linha balnear de trem, e consequente incorporação dos terrenos do Distrito, a empresa concessionária de Antonio Candido de Sequeira precisaria comprar os pequenos lotes que, segundo o documento, desvalorizavam a localidade por estarem abandonados. (FERREIRA, 2012).

Outro projeto realizado pela companhia, segundo o Guia, será o de arborização e arruamento. $O$ primeiro logo se faz sentir com a plantação ao longo da alameda de pinheiros, acácias e eucaliptos. Na faixa de terra mais próxima ao mar a plantação de "cedro marytimo" foi feita, pois esse tipo de planta apresenta a característica de fixação das dunas. Já o arruamento, por sua vez, se dava nesse processo de um novo traçado destinado aos terrenos, com o cercamento dos lotes para futura venda.

Ao perceber esses primeiros termos do Guia dos Banhistas, estamos diante de um conjunto de descrições, e ações práticas, que identificam claramente o manejo humano dentro de um ambiente em plena ressignificação. $\mathrm{O}$ ato que se dá na projeção de uma alameda a qual servirá de 
caminho até o mar, sendo essa obra perpendicular à praia de banhos, vislumbra uma modernidade que aqui não se relaciona tão somente ao uso dos banhos, mas ao ideário moderno, essencialmente, urbano do período - quando esse tipo de arruamento se transforma em símbolo de novas práticas sociais.

$\mathrm{E}$ se aqui o termo modernidade surge enquanto referência para o contexto, isso se faz pensando nas palavras de Marshall Berman quando diz:

Ser moderno é encontrar-se em um ambiente que promete aventura, poder alegria crescimento, autotransformação e transformação das coisas em redor mas ao mesmo tempo ameaça destruir tudo o que temos, tudo o que sabemos, tudo o que somos (BERMAN, 2007, p. 24).

Assim, o uso dessa natureza litorânea na forma de praia pode ser entendido como esse espaço da aventura, da ida ao desconhecido, que tanto enseja emoção nos sujeitos, causando transformações da ordem do sensível ao inserir-se nesse ambiente, como também expõe o "novo" enquanto medo. Porém, está nesse processo o que o próprio autor, em seguida, irá chamar de timbres e ritmos da modernidade, elementos que surgem das transformações da paisagem especialmente no século XIX.

Essa mesma modernidade propõe uma relação com o espaço natural, e que se dá não enquanto preocupação de seus usos, refletir nesse sentido seria elaborar uma análise anacrônica, já que as demandas desse período significam essa relação não a partir do viés do esgotamento eminente dos recursos naturais, mas sim de uma ocupação humana assentada nessa proposta de modernidade que percorria vários cantos do globo. Porém, é preciso pontuar que, mesmo assim, o tensionamento com essa natureza existe, os sujeitos se colocam num espaço do encontro com o natural, efetivamente, e a isso dão significados e estabelecem formas de acesso sensível.

Ao escolher a forma de uso de um espaço, que antes era considerado "abandonado", para agora ser ocupado por uma invenção balnear, o que está em jogo é claramente essa relação entre natureza e cultura, quando tais termos são dispostos enquanto polos em tudo distintos no âmbito ecossistêmico. Essa forma dicotômica, assim, é mais uma das formas humanas de pensar a natureza como esse "outro", podendo ser classificada como histórica a medida que é um constructo inventado, e que atravessa a experiência humana em suas formas de interação com o meio.

Carlos Walter Porto Gonçalves, pensando os conceitos de natureza criados pelos homens pontua: 
Toda sociedade, toda cultura cria, inventa, institui uma determinada ideia do que seja natureza. Nesse sentido, o conceito de natureza não é natural, sendo na verdade criado e instituído pelos homens. Constitui um dos pilares através do qual os homens erguem as suas relações sociais, sua produção material e espiritual, enfim, sua cultura (GONÇALVES, 2006, p. 23).

Num retorno ao texto, encontramos, ainda nesse capítulo, a seguinte passagem sobre a praia:

Ao Nordeste avista-se a duas léguas de distancia os estabelecimentos principais da praticagem da barra; ao Sudoeste descortina-se a praia lisa, resistente aos passos bem como às rodas dos vehiculos, que nenhuma depressão causam na areia; e emfrente, ao Sueste, vê-se o grande, o immenso oceano; em que a attenção se fixa por um longo tempo, admirando as suas bellezas, relembrando as suas virtudes, e também segredos que encerra de riqueza animal, e de valores, e vidas que sepultou (GUIA DOS BANHISTAS, 1890, p. 5-6).

Nesse trecho parece se coadunar boa parte daquele conjunto de representações sobre a praia, ou mesmo o mar, no Ocidente (CORBIN, 1989). Primeiro é importante destacar a perspectiva do Guia: ele organiza sua apresentação do mar posicionando-se a sua frente, propondo aí um banhista imaginário que deveria, da mesma forma, perceber tal cenário dentro dessa perspectiva - a instituição de uma forma de olhar, de sentir esse natural até então intocado.

A falsa percepção infinita, capaz de prender o olhar do espectador/banhista impressionado como se estivesse diante de uma pintura, seduz o olho humano, possuindo o desejo de uma beleza que remonta aos romances litorâneos do século XVIII. Estão presentes os "segredos", o desconhecido que se esconde por trás da linha do horizonte, aquele fim do mundo próprio do tempo das grandes navegações, e dos barcos desaparecidos em pleno oceano, elementos amplamente explorados por Alain Corbin (1989) quando aponta as origens da invenção da praia. Presente, também, os segredos que estão guardados nas profundezas desse mar, contribuindo para o "sepultamento" de vidas, sempre remontando a um imaginário no qual o desconhecido e a catástrofe caminham juntos.

O circuito de referências para a assimilação dessa natureza e paisagem se mostram em plena operação no Guia, já que podemos perceber nesse tipo de manifestação um fino diálogo com essas referências marítimas que permeavam o imaginário do período ligado ao mar, e suas apropriações no cotidiano oitocentista (CORBIN, 1989).

Sobre os dois itens seguintes é preciso retomar um elemento essencial ao enquadrar o Guia dos Banhistas, o diálogo que ele faz com o livro de 
Ramalho Ortigão, "As praias de Portugal", publicado em Lisboa no ano de 1876. Para entender como o Guia dos Banhistas acaba integrando ao seu texto esse material é preciso compreender que, tal autor, é considerado nesse período uma espécie de viajante português que se dedicava a descrever as praias do seu país, fazendo, assim, com que se estabeleça o desejo de conhecêlas (ZAN, 2009, p. 68).

Há uma escolha orientada por parte do Guia quando opta por importar esses dois capítulos, O Tratamento Maritimo, Precauções Hygienicas, deixando de lado qualquer tipo de produção local sobre o tema dos tratamentos terapêuticos ligados à maritimidade na costa do Rio Grande do Sul. E, quando o próprio documento anuncia que os dois próximos itens serão excertos do autor português, o faz da seguinte maneira:

Para evitarmos uma dissertação sobre assumpto que somos incompetentes, sem comtudo desprezarmos o que em seu excelente livro As praias de Portugal, aqui transcrevemos alguns trechos que n'aquelle livro encontramos de utilidade para o público (GUIA DOS BANHISTAS, 1890, p. 7).

O Guia não apresenta o texto de Ortigão na íntegra, mas sim a partir de trechos específicos. Omite, por exemplo, toda uma explicação sobre Hidrologia Médica baseada na água do mar, principalmente em estudos de cientistas franceses (ORTIGÃO, 1966). Ao retirar de si a responsabilidade dessa leitura medicinal dos banhos, dedicando-se textualmente aos outros itens, parece abrir-se brecha para um entendimento de praia atrelada muito mais as práticas de banho que reivindicariam a exploração financeira das estruturas criadas, do que propriamente a valorização de demandas médicas que poderiam ser objetivadas.

Stelio Marras acentua a importância de Ramalho Ortigão para uma popularização dos banhos no Brasil, sendo que suas crônicas percorriam a capital do Império apresentando a "novela da vida mundana, da vilegiatura e da cura, das experiências modernas de viagem. Tudo interesse vivo de um tempo que pretendia fruir a distinção entre lazer e trabalho" (MARRAS, 2004, p. 126). Com isso, havia um circuito textual desse autor no Império, o que dá sentido a sua utilização no interior do Guia dos Banhistas, e também não há que se desconsiderar o papel da Bibliotheca Rio-Grandense, mais uma vez, na disseminação desses tipo de material, já que a instituição recebia um grande fluxo de periódicos e revistas ilustradas durante o século XIX.

Logo no trecho inicial de $\mathrm{O}$ tratamento marítimo o Guia diz: "O banho pode ser considerado sob dois pontos de vista: como agente hydroterapico e como banho medicamentoso" (GUIA DOS BANHISTAS, 1890, p. 8). No 
primeiro caso o banho deve ser "curto" e a temperatura "mais fria", enquanto o outro formato a temperatura deve ser "mais elevada", alcançando um máximo "três quartos de hora" (GUIA DOS BANHISTAS, 1890, p. 8).

A necessidade de aliar aos banhos uma "regularidade de hábitos" ligados ao cotidiano alimentar, por exemplo, é explicitada pelo documento. E o GB além de informar que "a excitação do appetite produzidas pelos primeiros banhos" causa fadiga e sonolência, também indica uma alimentação em que devem ser excluídos "pratos irritantes, as substâncias difficeis de digerir" (GUIA DOS BANHISTAS, 1890, p. 9).

O que seria uma refeição ideal é logo apresentado dentro do guia:

O bife de vitella ou a costella de carneiro grelhada, os ovos quentes e uma pequena chavena de chá preto, ou simplesmente o bom leite fresco constituem uma alimentação incomparavelmente superior a do café com leite e do pão com manteiga... (GB, 1890, p. 9)

Ainda apresenta um cardápio noturno, no qual "ao jantar convem um regimen pouco animalisado. De carne de boi nunca deve haver mais de um prato" (GUIA DOS BANHISTAS, 1890, p. 10). E encaminha a finalização desse capítulo informando que:

É muito salutar o levantar cedo, passear a frescura da manhã, beber em jejum meio copo d'água fria. Se apparece alguma perturbação nas funcções do organismo, deve suspender-se o uso do banho até que o estado normal se reestabeleça $(\mathrm{GB}, 1890$, p. 10).

Sobre as Precauções Hygienicas, Segundo o Guia dos Banhistas o que "importa fazer" é preocupar-se com três momentos: "antes do banho, no banho e depois do banho" (1890, p. 11). Estruturado dessa forma, a questão inicial diz respeito ao fato do banhista já ter feito a digestão completa, e informa que o horário dos banhos também deve ser percebido, já que a partir desse critério se estabelecerá um tipo de sujeito:

Se o sujeito é robusto e procura apenas no banho a tonificação da água fria e a
espécie de massagem produzida pelo embate da vaga, a sua hora mais oportuna
é da manhã. Para as pessoas débeis que procuram no banho os effeitos da
composição chimica da água salgada sobre os tecidos, a hora mais conveniente é
das duas as cinco da tarde, quando por effeito do calor a temperatura do mar
sobe cinco ou seis graus (GUIA DOS BANHISTAS, 1890, p. 11)

Aqui é possível perceber a existência de uma divisão desse corpobanhista, que obedece ao horário matinal destinado aos saudáveis, ou àqueles que procuram nos banhos uma forma de tonificação, e o turno da tarde aos sujeitos que desejam algum tratamento medicinal. 
Nesse amplo espectro de situações que identificam uma relação dos sujeitos com o mar, o que está em jogo não é algo propriamente pensado para Villa Sequeira. Essas são leituras que Ortigão faz para Portugal, levando em conta o seu território e o seu universo de significados, imaginário, enfim, um repertório cultural próprio do outro lado do Atlântico - perder isso de vista seria um equívoco quando nos voltamos a esse texto.

Da mesma forma, ao inserir tais informações mobiliza-se um universo de sentidos que aqui é pensado a partir de um apontamento de Marcel Mauss, quando diz que "cada sociedade tem hábitos corporais que lhes são próprios" (MAUSS, 2004, p. 213). Com isso em mente, podemos dizer que o homem não é produto de seu corpo, mas em diferentes contextos é ele que faz de seu corpo um produto, um servir-se próprio das representações que estão em circulação.

Igualmente, o caráter de manual civilizatório se dá com essa "etiqueta corporal", como postura Le Breton (2007, p. 47). As normas explícitas e implícitas em que essa etiqueta opera parte do Guia dos Banhistas nesse caso, já que maneiras de engajar e servir-se do corpo no espaço são apresentadas não só na esfera da sociabilidade do balneário, mas também naquilo que tange o encontro dos sujeitos com o mar.

Após os rituais do banho, o documento passa a referenciar aquilo que chama de Commodidades na Praia. Nesse momento ele se preocupa em apresentar uma estrutura aprimorada em relação à temporada de banhos de 1890/1891:

100 camarotes para homens $-1^{\mathrm{a}}$ classe.

$100 "$ " senhoras $-1^{\text {a }}$ classe

$20 \quad " \quad$ " homens $-2^{\mathrm{a}}$ classe

20 " " senhoras $-2^{\text {a }}$ classe

50 barracas sobre rodas

Um restaurant elegant á la carte

Leitaria

Rouparia (recebimento e entrega de roupas de banho) (GUIA DOS BANHISTAS, 1890, p. 15).

Em sua forma física, os camarotes apresentam as seguintes características:

Os camarotes são construídos com solidez e elegância sobre um estrado fixo sobre estacas de madeira de lei, com porta vidraça, xadrez para o piso, banquinho, cabides para roupa, e espelho. $\mathrm{Na}$ frente ao mar corre uma varanda espaçosa, com balaustrada, corrimão e bancos, offerecendo desta forma toda a commodidade para os visitantes... (GUIA DO BANHISTAS, 1890, p. 16). 
$\mathrm{Na}$ areia da praia também se desenrolam atividades, conforme aponta o Guia serão "diversões possíveis": "corrida de cavallos, passeios em carruagens e trolys, jogo de bollas de borracha, cricket, trapésios, balanços, velocípedes, volante" (GUIA DOS BANHISTAS, 1890, p. 16).

No âmbito do que o Guia dos Banhistas considera como comodidades, o que se dá a ver é, também, a criação de uma paisagem manejada pelos sujeitos - primeiramente pelo proprietário que organizou esse conjunto de estruturas, depois a prática capaz de dotar de novos arranjos, a partir de suas estratégias cotidianas, esse mesmo cenário. Isso porque, ao dispor de estruturas físicas à beira-mar, numa ação antrópica planejada, forja-se um enquadramento do espaço natural, ou seja, a praia de banhos, nesse momento, é o que está inserido dentro desse perímetro dos camarotes e das cabines.

Será nesse perímetro que as práticas de praia irão ocorrer, dotando de sentido humano um determinado espaço instituído pela administração balnear, e descrito no Guia dos Banhistas como suporte de consolidação dessa proposta. Nesse sentido, podemos observar, justamente, o momento em que se estabelece uma construção cultural do olhar no ambiente costeiro, uma paisagem.

Para Thiago Sayão, que estudou a representação da paisagem na cidade de Florianópolis, destacando uma identidade litorânea para essa localidade que se forjava a partir da imbricação que foi efetivada entre natureza e cultura pelos sujeitos do século XIX, toda paisagem é uma:

\footnotetext{
composição sensível de acesso a cultura, uma forma de representação carregada de sentimentos, memórias e conhecimentos. Ela constrói laços de afinidade entre pessoas e ambiente, atribui sentido estético ao mundo que nos rodeia ao mesmo tempo em que age como verdadeira pedagogia do olhar (SAYÃO, 2011, p. 28).
}

Situando-se na exterioridade daquilo que é entendido como "natureza" para esses sujeitos do século XIX que inventaram praias, as estratégias de criação de paisagens são consideradas fundamentais para forjar esses "laços de afinidade entre pessoas e ambiente". No caso da Villa Sequeira, delimitar o que é praia a ser praticada valendo-se de estruturas como os camarotes e cabines, consequentemente, institui uma paisagem que se agrega ao imaginário dos banhistas de maneira sensível. Tal afirmação irá ganhar correspondência quando observamos o conjunto de postais elaborados pelo estúdio fotográfico dos irmãos Fontana, quando contratados por Sequeira para criação de um catálogo de imagens panorâmicas do balneário em 1890 (FERREIRA, 2012).

Nos últimos dois itens do Guia dos Banhistas, intitulados Habitações 
da Villa Sequeira e Salões de visitas e concertos e de jogos, o texto se dedica a apresentar as locações possíveis para os visitantes, bem como as oportunidades de sociabilidade. Ao contrário dos itens anteriores, a dedicação agora é ligada aos ambientes privados, e que por não serem o foco desse artigo, optamos em não modificar o horizonte de análise aqui estabelecido.

Por fim, em um dos últimos parágrafos do documento, ele informa sobre as obras de acesso ao canal portuário de Rio Grande, as quais não vieram a acontecer. E, da mesma forma, informa que no ano seguinte um novo Guia dos Banhistas seria confeccionado - o que também não ocorreu.

FIGURA 3 - Guia dos Banhistas, 1890.

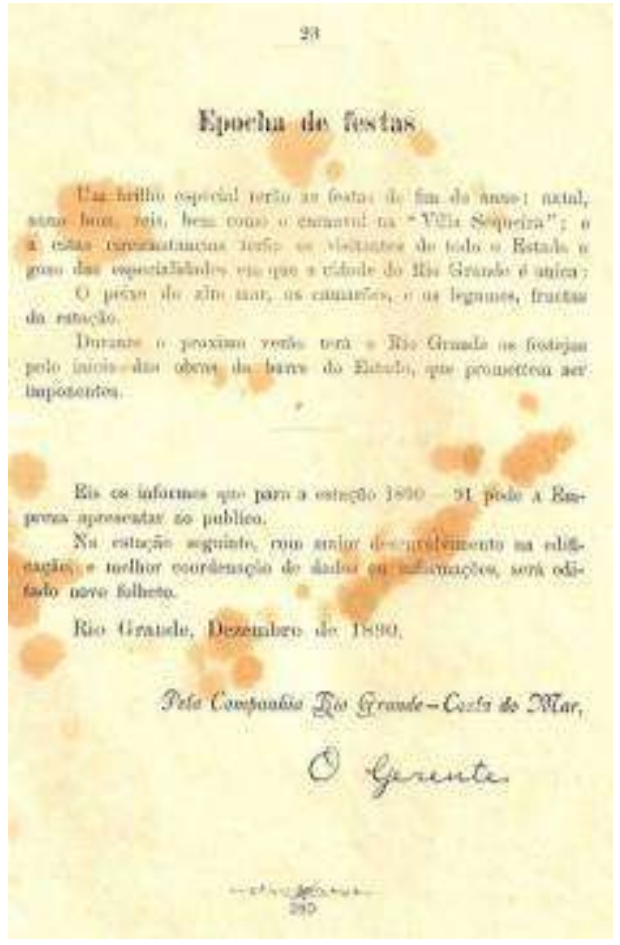

Fonte: Acervo do Centro Histórico de Documentação Histórica da Universidade Federal do Rio Grande - CDH/FURG 


\section{Considerações finais}

Esse texto começou com as duas locomotivas chegando no balneário Villa Sequeira, no ano de 1890. Ao encerrá-lo, parece ser possível retomar esse paralelo quando pensamos no final de um dia de praia, ou mesmo no final de um veraneio.

Ao retornar para cidade podemos dizer que os passageiros foram atravessados sensivelmente por essa experiência litorânea ligada aos banhos de mar, à invenção de uma praia nessa localidade, o que é algo significativo ao ponto de representar aos sujeitos uma novidade capaz de mobilizar um novo conjunto de representações que, dali em diante, seriam acessadas no cotidiano.

A praia passava a fazer parte da cidade, e as marcas deixadas podem ser vistas por diferentes espectros. No caso aqui apresentado foi através do Guia dos Banhistas que se deu a ler esse universo do sensível, o qual insere-se na cidade levando a pensar essa natureza costeira, antes abandonada para os critérios estabelecidos pelo documento, agora parte efetiva, ou mesmo lucrativa, da cidade de Rio Grande.

É a experiência da modernidade, a qual permeia o próprio documento, as ações dos sujeitos envolvidos que engajam-se em práticas que parecem representar o período histórico em questão. E nesse sentido, a alteridade que os sujeitos criam em relação à natureza, como esse fator externo, um outro, é parte desse processo moderno que dicotomizou esses elementos.

Porém, não seria por isso que os homens e mulheres do período deixariam de expressar essa relação - que nesse caso é de tensionamente constante -, a qual se projeta através das próprias ações humanas, e dos registros deixados. Ou seja, as marcas sensível estão presentes, basta que façamos àquela "modulação do olhar" aqui ilustrada logo no início do texto.

Desse esforço interpretativo, como diria Isabel Carvalho (2002), as sensibilidades ambientais emergem. E aqui elas surgem na confecção desse suporte chamado Guia dos Banhistas, quando as intencionalidades dos seus editores demarcam escolhas no processo de invenção de um modelo de praia, logo de um modelo de relação que desejam que os homens possuam com a natureza que visam explorar. Elas surgem no âmbito do modo de leitura que lhe é pensado, já que o caráter civilizatório do Guia demarca um formato de apropriação pedagógica junto aos leitores, impactando nas práticas estabelecidas.

E ainda, essas sensibilidades estão presentes na forma como os sujeitos irão significar cada uma dessas pré-condições que os idealizadores pretendiam. 
E aqui cabe trazer à tona, mais uma vez, a premissa de Chartier (2004) quanto a multiplicidade das modalidades de ler, e junto com isso a imprevisibilidade que surge a partir do contato dos leitores com o suporte.

A complexidade que surge a partir desse momento precisaria de um escopo de análise que ganhasse segmento a partir de agora, depois de exposto àquilo que consideramos os primeiros momentos dessa invenção da praia. Com isso, assim como um dia de verão, quando todos retornam para casa junto com o pôr do sol, esse texto também encontra o seu final, mas com a certeza que ainda há muita praia para contar.

\section{Referências}

BERMAN, Marshall. Tudo que é sólido desmancha no ar. São Paulo: Companhia das Letras, 2017.

BITTENCOURT, Ezio. Da rua ao teatro: os prazeres de uma cidade. Sociabilidades \& cultura no Brasil Meridional. $2^{\circ}$ ed. Rio Grande: FURG, 2007.

CAMPOS, Daniela Queiroz. Garotas modos e modas: a civilidade e a estética feminina na coluna garotas nos anos dourados. In: SIMPÓSIO INTERNACIONAL PROCESSO CIVILIZADOR, X, 2007, Campinas. (Anais Eletrônicos do X Simpósio Internacional Processo Civilizador). Campinas, São Paulo, 2007.

CARVALHO, Isabel Cristina de Moura. A invenção ecológica: narrativas e trajetórias da Educação Ambiental no Brasil. Porto Alegre: Editora da Universidade, 2002.

CHARTIER, Roger. A História Cultural: entre práticas e representações. Lisboa: Difel, 1990.

CHARTIER, Roger. Leituras e leitores na França do Antigo Regime. São Paulo: Editora Unesp, 2004.

CORBIN, Alain. Território do vazio: a praia no imaginário ocidental. São Paulo: Companhia das Letras, 1989.

ELIAS, Norbert. O processo civilizador. Vol. 1: uma história dos costumes. $2^{\mathrm{a}}$ Ed. Rio de Janeiro: Zahar, 2011.

FERREIRA, Felipe Nóbrega. Ao sul do sul o mar também é pampa. Sensibilidades de verão na Villa Sequeira (1884-1892). 2012. Dissertação 
(Mestrado em História) - Programa de Pós-Graduação em História da Universidade Federal do Rio Grande do Sul, Porto Alegre, 2012.

GONÇALVES, Carlos Walter. Os (des)caminhos do meio ambiente. 14 ed. São Paulo: Contexto, 2006.

GUIA DOS BANHISTAS - Informações sobre a praia e banhos na Villa Sequeira. Rio Grande: Typographia da Livraria Rio-Grandense, 1890.

LE BRETON, David. A sociologia do corpo. $2^{\mathrm{a}}$ ed. Petrópolis: Vozes, 2007.

LE GOFF, Jacques. História e Memória. $5^{a}$ ed. São Paulo: Editora da Unicamp, 2003.

LEFF, Enrique. $\mathbf{O}$ saber ambiental: sustentabilidade, racionalidade, complexidade, poder. Petrópolis/Rio de Janeiro: Vozes, 2001.

MARRAS, Stélio. A propósito das águas virtuosas. Formação e ocorrências de uma estação balneária no Brasil. Belo Horizonte: Ed. da UFMG, 2004.

MARTINS, Ana Luiza. Revistas em revista. São Paulo: Editora da USP, 2008.

MAUSS, Marcel. Sociologia e antropologia. São Paulo: Cosac Naify, 2004.

ORTIGÃO, Ramalho. As praias de Portugal. Guia do banhista e do viajante. Série Obras Completas. Lisboa/Portugal: Editora Livraria Clássica, 1966.

PESAVENTO, Sandra Jatahy. História e História Cultural. $2^{\mathrm{a}}$ ed. Belo Horizonte: Autêntica, 2008.

PESAVENTO, Sandra Jatahy. Sensibilidades no tempo, tempo das sensibilidades. Nuevo Mundo Mundos Nuevos, Coloquios, 2005. Disponível em: <URL: http://nuevomundo.revues.org/229> Acesso em: 04 set. 2011.

PESAVENTO, Sandra Jatahy. Sensibilidades: escrita e leitura da alma. In: PESAVENTO, Sandra; LANGUE, Frédérique. Sensibilidades na História: memórias singulares e identidades sociais. Porto Alegre: Editora da UFRGS, 2007.

PILLA, Maria Cecília Barreto Amorim. Manuais de Civilidade, Modelos de Civilização. História em revista, Pelotas, v. 9, p. 01-21, dezembro 2003.

SAYÃO, Thiago Juliano. (Re)Tratos insulares: a ilha de Santa Catarina vista através das representações das paisagens (1890-1940). 2011. Tese (Doutorado em História) - Programa de Pós-Graduação em História, Universidade Federal 
do Rio Grande do Sul, Porto Alegre, 2011.

STAROBINSKI, Jean. A literatura. In: LE GOFF, J. e NORA, P. História. Novas abordagens. Rio de Janeiro: Francisco Alves, 1988.

VALLEJA, Gustavo. El hilo de Ariadna: intercâmbios rioplatenses y estratégias comerciales urbanísticas de Francisco Piria. Sociohistorica, Buenos Aires, no 11-12, p. 99-133, 2002.

ZAN, João Carlos. Ramalho Ortigão e o Brasil. 2009. Tese (Doutorado em Estudos Comparados de Literatura e Língua Portuguesa) - Programa de PósGraduação em Letras, Universidade de São Paulo, São Paulo, 2009.

\footnotetext{
Abstract: The Swimmers Guide - Information about the swimming beach at Villa Sequeira was handed out on arrival at the railway station, and also had copies on the premises of the only hotel in this seaside resort town which was created in the year 1890 in the city of Rio Grand / RS. Thus, the present paper analyzes this document seeking to highlight the representations that are elaborated, and actuated, in both the sense of reading, and in the creation of a repertoire of sensibilities that were created from this intersection, previously unheard of in the Brazilian territory, between coastal nature and culture. Finally, from the process of disassembling this material, it will be possible to find a beach that goes beyond the text, and is related to the universe of representations, which endow the Guide with meaning, and also provide traces to what we call environmental sensitivities, which would be constituted from this permanent convergence of sea and land.
}

Keywords: Swimmers guide. Beach. Nature and culture. Reading. 